\title{
The ISSAS Model: Understanding the Information Needs of Sexual Assault Survivors on College Campuses
}

\section{Julia Skinner and Melissa Gross}

\begin{abstract}
Sexual assault is a prevalent, yet underreported and stigmatizing crime that disproportionately affects college-age students. The literature of Library \& Information Studies does not currently address the ways in which survivors may seek information after an assault. Blending findings from Psychology and LIS, this study proposes the Information Seeking of Sexual Assault Survivors (ISSAS) model, which examines the seeking process through various stages of healing. The article concludes with directions for future research as well as insights on serving survivors within the academic library while being mindful of one's appropriate professional role.
\end{abstract}

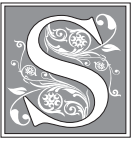

exual assault is a crime that impacts people from all walks of life. The National Crime Victim Survey reported 0.5 sexual assault per 1,000 U.S. women in 2009, ${ }^{1}$ with an average of 207,754 individuals being assaulted each year. ${ }^{2}$ In the United States, data from a variety of studies demonstrate that sexual assault on college campuses is a very real problem. ${ }^{3}$

However, it is difficult to know the full extent of the problem on college campuses, as sexual assault is a widely underreported crime because of the stigma survivors face. ${ }^{4}$ This stigma may also affect our ability to fully understand the extent of the problem and has implications for library service in terms of how, when, and if survivors of sexual assault will seek information related to recovery. The prevalence of sexual assault on college and university campuses suggests that improving services to survivors should be a part of LIS research and practice. However, reluctance on the part of survivors of sexual assault to self-identify, and the potential for researchers to do harm inadvertently to this population in the context of research, makes them a difficult population to study and to serve.

This article proposes a model for conceptualizing the information-seeking process of survivors of sexual assault through the lens of survivors' healing process. The objective of the Information Seeking of Survivors of Sexual Assault (ISSAS) model is to be informative about how survivors of sexual assault seek information as an aid to providing library services to this population, particularly in academic libraries. The ISSAS model, however, may be applied to sexual assault survivors in other contexts

Julia Skinner is Rare Books Curator at Kennesaw State University; e-mail: Jskinn27@kennesaw.edu. Melissa Gross is a Professor in the Information Department at Florida State University; e-mail: mgross@ fsu.edu. (C2017 Julia Skinner and Melissa Gross, Attribution-NonCommercial (http://creativecommons. org/licenses/by-nc/3.0/) CC BY-NC. 
as well. The article concludes with some thoughts for serving survivors and raising awareness, and for future research in this area, with a clear emphasis on respecting privacy and agency and maintaining an appropriate professional role.

\section{Related Literature}

Over the past fifteen years there have been some important studies focused on understanding the prevalence of sexual assaults on college campuses. The Sexual Victimization of College Women study ${ }^{5}$ surveyed 4,446 women who were attending college in fall 1996 and were invited to participate in the survey, which achieved a response rate of 85.6 percent. The number of respondents who experienced completed or attempted rape was 27.7 per 1,000 female students. These data report incidents over approximately six months.

The Campus Sexual Assault (CSA) Study sought both female and male students on two public university campuses to participate in the survey. ${ }^{6}$ The inclusion of males was an exploratory part of the study, however, and the final report focuses on female participants. The CSA also differs from the Sexual Victimization of College Women study in that it expands its investigation to include incapacitation of the victim, in which use of alcohol or drugs renders the victim incapable of consent as well as victims attacked while being asleep or unconscious, whether or not the perpetrator was responsible for the victim's incapacitation. Overall response rates were 42.2 percent and 42.8 percent for the two universities. Among participants, 28.5 percent of the 5,446 women said they had experienced an attempted or completed sexual assault either before or after entering college.

In 2014, the Community Attitudes on Sexual Assault (CASA) study ${ }^{7}$ was performed at the Massachusetts Institute of Technology to understand student perceptions of social behavior including sexual assault and misconduct. This survey achieved a 35 percent response rate (3,232 male and female respondents) and revealed 11 percent of the female undergraduate respondents had been sexually assaulted or raped as compared to 2 percent of male undergraduates, 3 percent of female graduate students, and 1 percent of male graduate students.

The 2015 AAU Campus Survey on Sexual Assault and Sexual Misconduct ${ }^{8}$ was undertaken with the goal of providing incidence and prevalence data, as well as the experiences and attitudes of students, to inform policy development related to preventing and responding to sexual assault and misconduct on campus. Twentyseven institutions of higher education participated in the survey in the spring of 2015, resulting in 150,072 students participating in the study. The overall response rate was 19.3 percent. They found that the rates of sexual assault vary widely between campuses, but that "average rates of nonconsensual contact by physical force or incapacitation across all 27 IHEs are as high or slightly higher than those revealed in previous surveys." 9

These studies agree that the risk of sexual assault is higher for undergraduates than for graduates and for women than for men. Risk is higher for freshmen and sophomores than for juniors and seniors. The AAU study ${ }^{10}$ found that students who identified as transgender, genderqueer or nonconforming, questioning, or not listed (referred to as TGQN in the report) were most at risk for sexual assault by force or through incapacitation (12\% for undergraduates) followed by undergraduate women $(10.8 \%)$, and TGQN graduate students $(8.3 \%)$. Perpetrators are most often someone the victim knows, such as a boyfriend, classmate, friend, acquaintance, or coworker. Most assaults take place off campus, often in a residence.

These studies agree that sexual assault is often unreported because survivors are not sure that what has happened is important enough to report, feel embarrassed or 
ashamed, feel reporting would be too emotionally difficult, feel they lack proof, are afraid of reprisals, or believe the police will not take the report seriously.

\section{Library Responses to Survivors of Sexual Assault}

A review of the LIS literature reveals little formal research that specifically addresses the needs of sexual assault survivors. The only article that explicitly addresses sexual assault is Wilmoth's $2008{ }^{11}$ work on incorporating empowerment counseling into the reference interview. Sexual assault is more widely discussed in other social sciences, such as psychology, and includes studies of post-assault social support resources ${ }^{12}$ and the impact of post-traumatic stress disorder (PTSD). ${ }^{13}$ The Information Seeking of Sexual Assault Survivors (ISSAS) model addresses this gap in the literature by offering a way to conceptualize the information-seeking process, taking into account the stages of healing encountered by a survivor.

For the most part, existing articles emphasize form and content of resources. For example, Finn ${ }^{14}$ argues that the Internet opened the door for service agencies working with domestic violence survivors to more easily reach their service populations. Hartman ${ }^{15}$ built on this by providing an annotated bibliography of different online resources for survivors, to be used by reference librarians.

Finn, Westbrook, Chen, and Mensah ${ }^{16}$ argue that resolving crises involves information work, and it is important that agencies develop information expertise to effectively meet the needs of those in crisis. This points to the importance of creating the ISSAS model, as articulating an information need is the first step in beginning to address that need effectively. The later work of Westbrook ${ }^{17}$ involved interviews with law enforcement, domestic violence shelters, and survivors to understand what aspects of information were most valuable for domestic violence materials being shared with survivors by law enforcement. Important aspects of information include content (such as information written in plain and understandable language) as well as form (such as small printed materials that could be concealed easily). Practical findings provide the basis for comparison with the model and could result in theoretically based findings that can be translated from the law enforcement context to the library context to serve survivors most effectively.

In addition, only one article ${ }^{18}$ explicitly focuses on using a theoretical framework as an avenue for understanding intimate partner violence. There is some overlap with the ISSAS model that is discussed in detail later on; however, the lack of more theoretically informed work in describing the information needs of violence survivors highlights the importance of creating such a model.

Libraries have adopted a user-centered focus since the passing of the Library Bill of Rights, ${ }^{19}$ including reaching out to underserved populations, such as the homeless. ${ }^{20}$ Serving populations that may be hesitant to self-identify is one way libraries can continue the tradition of user-focused services, by providing needed information to those who may or may not be willing to ask for it, based on an understanding of the information-seeking needs of specific populations. While we focus on academic libraries' service of college-aged survivors in this article, the suggestions for practical applications of this model and the use of the model itself may apply to other survivors of sexual assault and to public libraries as well.

Providing services to populations who may not want to self-identify raises a number of practical issues. First of all, identifying survivors (or asking them to self-identify) is unethical at best, making it impossible to take an exact count of how many such users visit a library and/or use its online resources. While analytics can be viewed for a web resource, these do not say how many of those visitors are using the site as a part of their own healing process, versus another purpose (for instance, as a resource for a class project, or something stumbled upon on accident). 
Finally, the issue of professional role is an incredibly important one to address. Librarians are not counselors, law enforcement officials, or medical professionals, and it is important to share resources with survivors in a way that is consistent with the profession of librarianship, the provision of information. ${ }^{21}$ Academic librarians should know that, if a member of their college or university community (student, staff, or faculty) divulges an incident of sexual violence, misconduct, or harassment to them, they have a responsibility to report the incident. This mandate is a legal one under what is known as Title IX.

Title IX is a law that many associate with gender equity, particularly girls' participation in sports. However, Title IX has other provisions including a provision that requires schools to have procedures in place for dealing with complaints of sexual harassment and assault. ${ }^{22}$ These procedures must include instructions for filing a complaint and outline how to support victims of sexual violence. College and university employees are required to report knowledge of sexual misconduct. For this reason, it is important to be aware of the related Title IX policies and procedures as well as the contact information for campus resources provided to assist survivors of sexual assault.

\section{The Information Seeking of Sexual Assault Survivors (ISSAS) Model}

The ISSAS model is based on models of help seeking and recovery developed in the field of psychology. ${ }^{23}$ In addition, sense-making theory ${ }^{24}$ provides a framework for the process of constructing meaning through the healing process. The model is also informed by the principles of information seeking outlined by Harris and Dewdney. ${ }^{25}$ Harris and Dewdney interviewed 543 women from six different communities, followed by interviews with 179 service providers, to understand the women's information needs and how those aligned with the responses to these needs. The comparison of these interviews revealed that domestic violence survivors' needs and expectations were not being adequately met by existing systems and services.

One key finding from their study is that "help seeking is affected by factors unique to each person's situation and the decision to seek or not seek help is affected by a number of variables." ${ }^{26}$ This means that strictly using demographic variables as a predictor of help-seeking behavior may be ineffective; therefore, it is better to think of seeking in a situational context, where abused women turn to informal and formal resources like other information seekers. ${ }^{27}$ They also found that one major barrier was that women knew what kind of help they wanted but were unable to find this help within their communities. Using their extensive set of interviews as a basis, they constructed a set of six principles regarding the information-seeking behaviors of domestic violence survivors, although they argue these principles are broad enough to be applied to ordinary information-seekers as well. The six principles are: ${ }^{28}$

1. information needs arise from the help-seeker's situation;

2. the decision to seek help or not seek help is affected by many factors;

3. people tend to seek information that is most accessible;

4 . people tend to first seek help or information from interpersonal sources, especially from people like themselves;

5. information seekers expect emotional support; and

6. people follow habitual patterns in seeking information.

Kennedy et al. ${ }^{29}$ also informed the process of seeking information conceptualized in the model. In their model of the help-attainment process, they situate the individual's help-attainment activities within a nested series of contexts. These include: social location, prior cumulative adversity/victimization/stress, community context/resources, and developmental/situational context. Within the help-attainment process, the individual appraises their needs and the perceived availability of help before engaging in formal 
help-seeking, moving through whatever system is necessary to attain that help before having their needs met and experiencing improved mental health outcomes. They also envision interventions to improve help attainment as taking place within any of these stages, which may be a useful avenue for future researchers to explore.

Elements from this model were adapted in the ISSAS model to isolate the process of information seeking and to situate the person as moving through a series of enablers and barriers as she or he seeks information. This allows the ISSAS model to be adaptable to different information environments, depending on the specific need, availability of help, and so on.

The primary context surrounding the survivor in the ISSAS model is the three stages of recovery outlined by Harney, Lebowitz, and Harvey. ${ }^{30}$ These three stages (restoration of safety, remembrance and mourning, reconnecting with others) are situated around the user and provide the context in which the information need erupts and in which the individual constructs meaning. The survivor moves through these stages, which are situated in the model as an external framework that the survivor navigates as he or she manages the internal process of healing. The ISSAS model (provided in figure 1 below) assumes that the individual may or may not self-identify. The stages of healing that underlie the appraisal of needs are named and bounded by a framework not created by the user but that provide a lens for understanding the gap(s) a user is facing. This is similar to Dunne's ${ }^{31}$ "persons-in-progressive-situations" approach that envisions domestic violence survivors as moving through different situations that are defined by different needs. Dervin ${ }^{32}$ argues that searchers are always constructing sense and that sense-making is an intensely personal experience. The three stages of healing, as well as the enablers and barriers for seeking information, are a part of that personal context and personal sense-making process.

The work of Harris and Dewdney ${ }^{33}$ pulls in a variety of information-seeking models, including Dervin's sense-making theory, to build six principles commonly found across the literature. They argue that information seeking is situational and that the decision to seek (or not) is based on many factors. These principles are addressed in the enablers and barriers in the model, as well as the stages of healing that continuously surround the survivor. Importantly, they, like Kennedy et al., ${ }^{34}$ point to the importance of interpersonal sources in the seeking process, which is addressed as a seeking stream separate from seeking through documents or through formal help channels.

\section{Navigating the ISSAS Model}

The ISSAS model focuses on a series of interrelated decision points that a sexual assault survivor may experience throughout the healing process. It starts with the recognition that information is needed to move forward, in the way that sense-making theory ${ }^{35}$ seeks to understand a user's specific context and the gap that is inhibiting his or her ability to reach a goal or to make meaning of experience. For survivors of sexual assault, there are several decision points on the information-seeking path. As is demonstrated in the discussion below, each decision point carries with it the danger that the desire to seek information may be blunted by various perceptions and conditions. If a decision point is reached, and the survivor feels that the decision to move forward through the information-seeking process is not an option, then that particular instance of information seeking ends. However, the information-seeking process can be picked up anytime during the healing process. The context will change as the survivor heals; and, as it does, the way the survivor constructs meaning will change as well. In a perfect world, the process of information seeking that facilitates making meaning and healing would be self-perpetuated and help move the survivor toward a reestablished sense of agency and identity as the individual is increasingly able to integrate what has happened into his or her personal narrative. 


\section{Decision Point: Appraisal of Needs}

The situation that the user faces in the ISSAS model is explicated by the stages of healing, which involve reestablishing a sense of safety, remembrance, and mourning, as well as reconnecting with others. ${ }^{36}$ In line with sense-making theory, this is the context the user is facing, which leads to an appraisal of information needs that will assist the user in moving forward. Here Harney, Lebowitz, and Harvey's healing stages ${ }^{37}$ are adapted into the model, as personal contexts that surround the survivor and impact interactions with larger contexts and with information. The contexts surround the user during the needs appraisal process.

Stage One refers to the early stages of healing, described in Harney, Lebowitz, and Harvey as a process of meeting initial needs in the aftermath of an assault, such as seeking medical care and beginning to reestablish trust with the world around them. Stage Two refers to Harney, Lebowitz, and Harvey's idea of remembrance and mourning, which is the stage where emotional recovery and encountering the associated loss and trauma (such as feeling a loss of agency) begins to take place. Finally, Stage Three refers to the concept of reconnecting with others, where the survivor feels like trust and feelings of safety have been restored to the extent that the survivor can begin to allow others back into her or his life.

In the ISSAS model, the information-seeking process begins with appraising a need, which is informed by the stage of healing a person is experiencing (for example, needs in Stage One have to do with reestablishing a sense of safety, perhaps by locating a safe place to stay). Upon recognizing the need, the person considers whether help is available. The double arrow between appraisal of needs and perception of available help indicates that, if the person does not perceive that help is available, she or he is not going to continue the process of seeking that help and may go back to reassess needs-or may decide that for now the need cannot be met.

\section{Decision Point: Perception of the Availability of Help}

Once the survivor has determined what the need is, the next step is to determine whether help is available. As mentioned previously, sexual assault often results in feelings of shame and embarrassment, ${ }^{38}$ and this can cause a survivor to feel hesitant about the availability of help. Additionally, Harris et al. ${ }^{39}$ point to a disconnect between survivors' needs and available resources within communities, creating another potential barrier in the information-seeking process. Presuming the individual perceives help as being available, she or he then moves through a variety of enablers and barriers in locating that help. ("Help" here includes information that is helpful to the situation, as well as assistance from individuals or organizations.)

\section{Decision Point: Enablers and Barriers}

Enablers include contexts such as socioeconomic status as discussed earlier from Kennedy et al., ${ }^{40}$ and Veinot's dynamic view of social capital, ${ }^{41}$ which envisions access to information as a function of a survivor's social networks. For example, a survivor with a rich and varied network will be better poised to access a variety of resources than an individual who is more isolated. These can be envisioned as playing a different role or having a different degree of impact, depending on the situation, and point to Harris and Dewdney's six principles ${ }^{42}$ mentioned previously. Some examples of barriers include socioeconomic status, severity of affective issues, previous experiences, developmental level, social location, and the stigma associated with being a survivor. Barriers can also exist outside the survivor, possibly including things like catalog headings ${ }^{43}$ or a lack of available resources. Enablers are contexts that increase access. These might include Internet access, a strong interpersonal support network, or the ability 
to leverage financial resources to leave an unsafe situation. Just like barriers, enablers can also exist outside the individual. For example, a welcoming and helpful librarian can be an enabler for a survivor seeking information in the library.

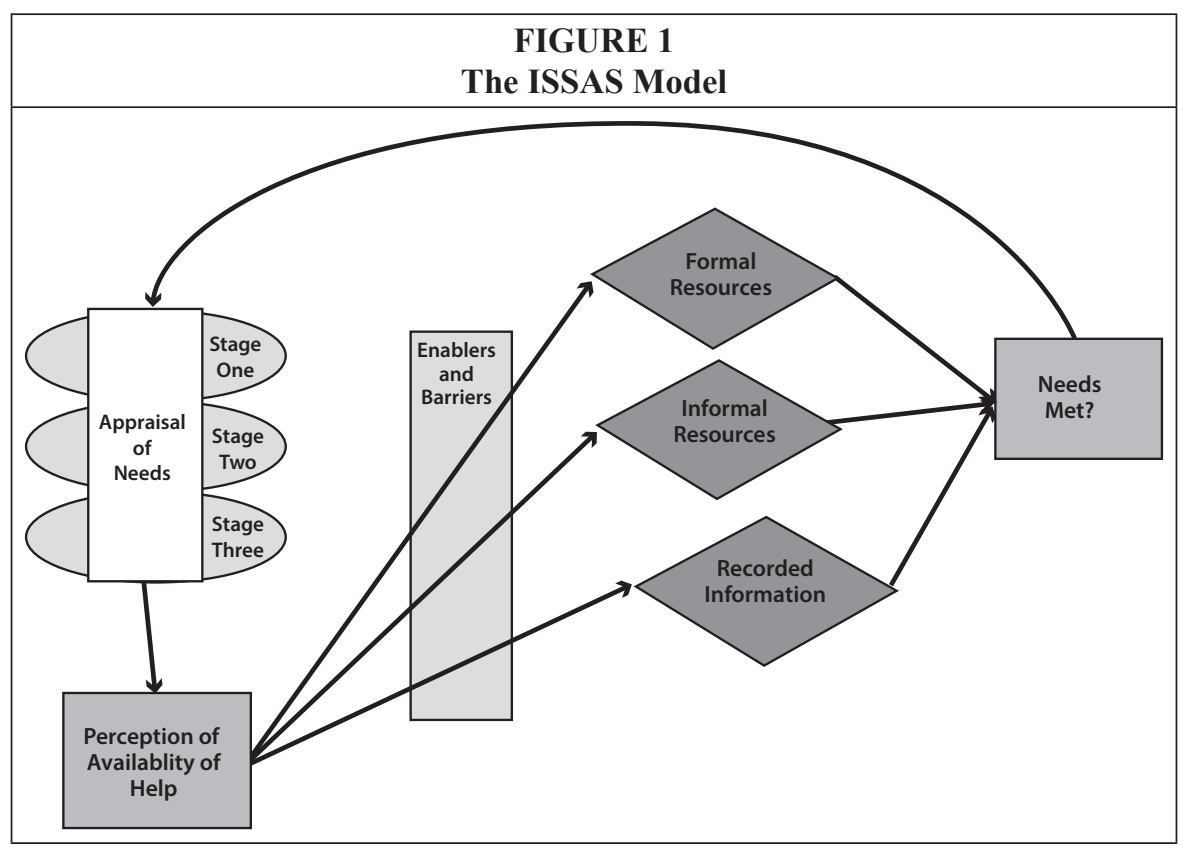

\section{Decision Point: Selecting Information Sources.}

The impact of these enablers and barriers may vary depending on what kinds of resources are sought.

Formal resources can be people, institutions, or recorded information. "Expert" help providers may include law enforcement, crisis teams, counselors, allied health, help lines, and the like. On campus, these include many equivalent resources such as campus police, student counseling, and victims' advocates. All of these resources, in the library and elsewhere, may be perceived as more or less accessible based on an individual's context, awareness of these resources, and understanding of the extent to which these resources will be responsive to the survivor of sexual assault. Formal institutional resources include police, hospitals, and rape crisis teams (organizations/ institutions that serve those in crisis). Formal resources also include those resources that are available on campus such as campus security, the campus counseling center, and victim advocates. Formal resources can include resources available through the library.

Informal resources are people. These resources are nonexpert individuals who are trusted by the seeker, even if they lack the trained perspective of formal providers. The most obvious people who might fill this role are friends and family.

Recorded information can be recorded in digital or tangible form, but it is a separate category because it indicates an end point that is an item, rather than an item provided by a human or institutional intermediary, or a piece of information sought to connect with individuals or institutions (such as online forums or contact information for a crisis team). An example of recorded information might be a website that outlines the side effects of different "date rape drugs," or a book on the healing process. When using these information sources, a survivor is turning to resources as sources of information 
rather than as connections to formal or informal resources. This also refers to information housed within the campus library. An example might be turning to a website to see what the website says about the healing process, rather than using a search engine to locate a formal organization or a support forum.

\section{Decision Point: Assessing Answers}

After completing the seeking process and receiving whatever help was available, the individual engages in a reassessment to determine whether the need he or she presented was met. If it was, the individual may continue through the seeking process with a new need or she or he may stop seeking information for a time while integrating new information into the healing process. If the information need was not met, the individual may choose to reframe a need or seek information through different channels. She or he may also conclude that no help is available, may stop trying to meet that need, and instead go through the cycle with another need. This demonstrates that the cycle is iterative, as the individual continues to construct personal meaning as he or she experiences new contexts and gaps along the road to healing.

\section{Significance of the ISSAS Model to LIS}

The study of survivors of sexual assault will contribute to the development of a better understanding of the information environment and user expectation and behaviors. Study of survivors of sexual assault can also inform investigation of information seeking and information provision to other groups who may not wish to self-identify, but whose need for information is compelling. Thus the ISSAS model is valuable for researchers seeking a framework to conceptualize investigation of the information needs of users who do not wish to self-identify their contexts when seeking assistance in the library. Findings from this study will provide a foundation for future research, inform professional practice and policy, and may result in improved information services.

\section{Implications for Library Programming and Services}

The ISSAS model recognizes that survivors of sexual assault may or may not wish to self-identify when seeking information related to their experience and healing process. It is an assumption of the model that information professionals can better assist survivors of sexual assault if they better understand the information needs of survivors of sexual assault as related to healing, constructing meaning, and the ways this process can be interrupted or enabled.

The goal of this model is not only to articulate how healing takes place but also to use that understanding to create better library services for survivors of sexual assault. As mentioned above, it is also important to use the model to inform respectful and helpful programming and services that are aware of the librarian's role as an information professional and that do not attempt to step into other roles for which they are not trained (such as psychologist or lawyer).

Further work is necessary to identify exactly how survivors' needs might be best met, but the ISSAS model provides guidance to practitioners in the selection of resources that speak to the different healing stages. These materials can be made available and advertised on the library's website or elsewhere, so survivors know they are available.

One important consideration for practitioners is how to provide access to resources in a way that does not force survivors to self-identify, such as by embedding it in the library's website where it does not look like a separate resource (perhaps in the same format as a LibGuide) or by providing guidance via signage to a section of books in the stacks that deal with issues of assault and healing, without having any separate signage near those items. Emphasizing a reference resource, such as text chat through 
the library site, as a way to ask staff about relevant resources without coming up to the desk and self-identifying may also be a useful approach.

Westbrook has also developed a model for information services for people in cri$\mathrm{sis}^{44}$ based on her work on intimate partner violence and an exploration of the social responsibility of libraries to the community. Her model emphasizes, among other things, the library as a safe space, the need to provide services in a respectful and emotionally supportive way, the importance for helping survivors develop information skills, particularly in the area of evaluating information, and the need for staff training in working with patrons in crisis. Westbrook offers that "reiterative, cyclical micro-information engagements support a gradual identity shift whose nature is set by the Survivor's mastery of changes, if any." 45

For academic librarians, it is important to be aware of campus resources, electronic and paper-based resources, as well as their Title IX responsibilities and procedures. The question of professional role comes into play here because librarians and faculty do not have the kind of confidential relationship with users that physicians, psychologists, and counselors on campus have. As each campus has its own specific reporting procedures, librarians need to know what is required of them when they are made aware of an incident of any kind of sexual misconduct.

There are a variety of resources for each healing stage that librarians might turn to. Stage One focuses on the immediate aftermath of an assault, as well as the survivor's need to establish safety. Survivors in this stage may benefit from information about resources like campus police and victims' advocates, as well as information about what sexual assault is and what some options are moving forward (such as resources from nonprofits that work with survivors). Survivors in Stage Two have established a sense of immediate safety and are concerned with remembrance and mourning. Information on healing processes, such as works on the stages of grief or on overcoming trauma, may be appropriate here. Information about self-care and emotional well-being, as well as information on peer support groups, may be helpful for survivors seeking to work through the traumatic experience as they move toward reconnecting with others.

Allowing others back into the survivors' world is the focus of Stage Three, and survivors in this stage may also benefit from the interpersonal connections found in something like a peer support group. They may also benefit from personal narratives of other survivors, as well as resources that focus on activities or hobbies that could help them reintegrate into the community (such as resources on campus groups, as well as resources on cultivating a given interest). Some resources may cross all three stages. For example, the narratives of survivors mentioned in Stage Three may be helpful for survivors in earlier stages, who may also want to see what others before them have done to cope with assault. Additionally, resources like a campus counseling center may be valuable across all stages, as the counselors there can help address the needs of survivors as they negotiate each stage.

\section{Implications for Research}

This model is the first step in what could be a rich research stream by the authors and other researchers. The authors would like to use the Delphi method as a possible avenue for testing the model in future research. In the Delphi method, subject area experts are consulted for their feedback and then read feedback from other experts and share additional thoughts they may have. This allows experts to benefit from the ideas of their colleagues, potentially providing deeper feedback or triggering newer ideas than they may have otherwise shared. The authors would like to share the model with experts in a wide range of helping professions, including medical staff who interact with survivors, those working at nonprofits such as rape crisis teams, and law enforcement. 
Eventually, the findings could result in the creation of a shell web resource that institutions could customize (for example, contact information for local nonprofit organizations in addition to national ones), and this could be incorporated into libraries' web presence as a way to serve patrons.

The authors would also like to explore how strong and weak ties ${ }^{46}$ function within survivors' information-seeking processes. Because of the very personal nature of this crime and survivors' concerns over self-identification, it is possible that existing work on information seeking may not fully apply to this subpopulation. This lends itself to the study of the impact of strong and weak ties on survivors' seeking behaviors and evaluation of resources, so this can be compared to what we already know about information seeking in general.

Finally, this model, which looks at information seeking as a process contextualized within a larger (and changing) healing process, could also serve as the basis for research and model creation related to research on other populations engaged in healing processes (such as natural disaster survivors). It may even be valuable to compare these different models to discern similarities and differences in information seeking during healing and to understand how these might inform resource creation and sharing.

\section{Summary and Conclusions}

Existing literature in Library and Information Science does not adequately address the information-seeking behaviors and information needs of sexual assault survivors, which is a sizable group of people who often are hesitant to self-identify. The ISSAS model builds on theories from psychology and literature on survivors of interpersonal violence from within the field of Library and Information Science to construct a theory of information seeking specific to sexual assault survivors within the library setting.

The model shows survivors existing within, and interacting with, changing contexts that impact their ability to access and use a variety of information sources. This approach can inform practitioners about the best ways to provide information, by emphasizing a variety of resource types that survivors can access without self-identifying. Future research should continue to refine and test the model to strengthen it and make it more useful to practitioners and other researchers.

\section{Notes}

1. Jennifer L. Truman and Michael R. Rand, Criminal Victimization, Report No. NCJ231327 (U.S. Bureau of Justice Statistics, October 2010), available online at http://bjs.ojp.usdoj.gov/content/ pub/pdf/cv09.pdf [accessed 25 October 2015].

2. Rape, Abuse, and Incest National Network (RAINN), How Often Does Sexual Assault Occur? (2009), available online at https://rainn.org/statistics [accessed 25 October 2015].

3. David Cantor, Bonnie Fisher, Susan Chibnall, Reanne Townsend, Hyunshik Lee, Carol Bruce, and Gail Thomas, Report on the AAU Campus Survey on Sexual Assault and Sexual Misconduct (2015), prepared for the Association of American Universities (Rockville, Mass.: Westat), available online at accessed October 25, 2015, www.aau.edu/uploadedFiles/AAU_Publications/ AAU_Reports/Sexual_Assault_Campus_Survey/Report\%20on $\% 20$ the $\% 20$ AAU\%20Campus\%20 Climate\%20Survey\%20on\%20Sexual\%20Assault\%20and\%20Sexual\%20Misconduct.pdf [accessed 25 October 2015]; Bonnie S. Fisher, Francis T. Cullen, and Michael G. Turner, The Sexual Victimization of College Women, Report No. NCJ 182369 (U.S. Department of Justice, 2000), available online at https://www.ncjrs.gov/pdffiles1/nij/182369.pdf [accessed 25 October 2015]; Christopher P. Krebs, Christine H. Lindquist, Tara D. Warner, Bonnie S. Fisher, and Sandra L. Martin, The Campus Sexual Assault (CSA) Study Final Report, NIJ Grant No. 2004-WG-BX-0010 (Washington, D.C.: National Institute of Justice, Dec. 2007), available online at https://www.ncjrs.gov/pdffiles1/ nij/grants/221153.pdf [accessed 25 October 2015]; Massachusetts Institute of Technology, Survey Results: 2014 Community Attitudes on Sexual Assault, available online at http://web.mit.edu/surveys/ health/MIT-CASA-Survey-Summary.pdf [accessed 25 October 2015]. 
4. Fisher, Cullen, and Turner, The Sexual Victimization of College Women; Callie Marie Rennison, Rape and Sexual Assault: Reporting to Police and Medical Attention, 1992-2000, Report No. NCJ 194530. (Washington, D.C.: U.S. Bureau of Justice Statistics, 2002), available online at www.bjs. gov/content/pub/pdf/rsarp00.pdf [accessed 25 October 2015].

5. Fisher, Cullen, and Turner, The Sexual Victimization of College Women.

6. Krebs et al., The Campus Sexual Assault (CSA) Study Final Report.

7. Massachusetts Institute of Technology, Survey Results: 2014 Community Attitudes on Sexual Assault.

8. Cantor et al., Report on the AAU Campus Survey on Sexual Assault and Sexual Misconduct.

9. Ibid., iv.

10. Ibid.

11. Wendy S. Wilmoth, "Serving Sexual Assault Survivors in the Academic Library: Using the Tools of Crisis Intervention and Empowerment Counseling in the Reference Interview," Georgia Library Quarterly 45, no. 1 (2008): 9-13.

12. Jacqueline M. Golding, Judith M. Siege, Susan B. Sorenson, M. Audrey Burnam, and Judith A. Stein, "Social Support Sources Following Sexual Assault," Journal of Community Psychology 17, no. 1 (1989): 92-107.

13. Maren Westphal, Mark Olfson, Marc J. Gameroff, Priya Wickramaratne, Daniel J. Pilowsky, Richard Neugebauer, Rafael Lantigua, Steven Shea, and Yuval Neria, "Functional Impairment in Adults with Past Posttraumatic Stress Disorder: Findings from Primary Care," Depression and Anxiety 28, no. 8 (2011): 686-95.

14. Jerry Finn, "Domestic Violence Organizations on the Web: A New Arena for Domestic Violence Services," Violence Against Women 6, no. 1 (2000): 80-102.

15. Linda Hartman, "Resources for the Many Faces of Domestic Violence," Medical Reference Services Quarterly 21, no. 4 (2002): 41-48.

16. Jeanine Finn, Lynn Westbrook, Tiffany Chen, and Priscilla Mensah, "Unprepared for Information Interactions: Abuse Survivors and Police," Journal of Documentation 67, no. 6 (2011): 933-57.

17. Lynn Westbrook, "Guidelines for Mandated Documents: Law Enforcement and Intimate Partner Violence Survivors," Journal of Documentation 71, no. 1 (2015): 25-51.

18. Lynn Westbrook and Jeanine Finn, "Community Information as Boundary Object: Police Responsibility for Abuse Survivors," Journal of Documentation 68, no. 6 (2012): 806-25.

19. Louise S. Robbins, Censorship and the American Library: The American Library Association's Response to Threats to Intellectual Freedom, 1939-1969 (Westport, Conn.: Greenwood Press. 1996).

20. For example, see: Lydia N. Collins, Francis Howard, and Angie Miraflor, "Addressing the Needs of the Homeless: A San Jose Library Partnership Approach," Reference Librarian 50, no. 1 (2009): 109-16.

21. For more information on issues of professional liability in the information professions, see: Paul D. Healey, Professional Liability Issues for Librarians and Information Professionals (New York, N.Y.: Neal Shuman, Inc., 2008).

22. United States Department of Education, "Title IX and Sex Discrimination" (Apr. 29, 2015), available online at http://www2.ed.gov/about/offices/list/ocr/docs/tix_dis.html [accessed 24 October 2015].

23. Patricia A. Harney, Leslie Lebowitz, and Mary R. Harvey, "A Stage by Dimension Model of Trauma Recovery: Application to Practice," Clinical Psychology 3, no. 4 (1997): 91-103; Angie Kennedy, Adrienne Adams, Deborah Bybee, Rebecca Campbell, Sheryl Kubiak, and Cris Sullivan, "A Model of Sexually and Physically Victimized Women's Process of Attaining Effective Formal Help Over Time: The Role of Social Location, Context, and Intervention," American Journal of Community Psychology 50, no. 1/2 (2012): 217-28.

24. Brenda Dervin and Patricia Dewdney, "Neutral Questioning: A New Approach to the Reference Interview," Reference Quarterly 25 (Summer 1986): 506-13.

25. Roma M. Harris and Patricia Dewdney, Barriers to Information: How Formal Systems Fail Battered Women (Westport, Conn.: Greenwood Press, 1994).

26. Roma M. Harris, Judy Stickney, Carolyn Grasley, Gail Hutchinson, Lorraine Greaves, and Terry Boyd, "Searching for Help and Information: Abused Women Speak Out," Library \& Information Science Research 23, no. 2 (2001): 123-41.

27. Ibid.

28. Harris and Dewdney, Barriers to Information, 19-27.

29. Kennedy et al., "A Model of Sexually and Physically Victimized Women's Process."

30. Harney, Lebowitz, and Harvey, "A Stage by Dimension Model of Trauma Recovery."

31. Jennifer E. Dunne, "Information Seeking and Use by Battered Women: A 'Persons-InProgressive-Situations' Approach," Library \& Information Science Research 24, no. 4 (2002): 343-55.

32. Brenda Dervin, "From the Mind's Eye to the User: The Sense-Making Qualitative-Quanti- 
tative Methodology," in Qualitative Research in Information Management, eds. Jack D. Glazier and Ronald R. Powell (Englewood, Colo.: Libraries Unlimited, 1992), 61-84.

33. Harris and Dewdney, Barriers to Information.

34. Kennedy et al., "A Model of Sexually and Physically Victimized Women's Process."

35. Dervin and Dewdney, "Neutral Questioning."

36. Harney, Lebowitz, and Harvey, "A Stage by Dimension Model of Trauma Recovery."

37. Ibid.

38. Cantor et al., Report on the AAU Campus Survey.

39. Harris et al., "Searching for Help and Information."

40. Kennedy et al., "A Model of Sexually and Physically Victimized Women's Process."

41. Tiffany Veinot, "A Multilevel Model of HIV/AIDS Information/Help Network Development," Journal of Documentation 66, no. 6 (2010): 875-905.

42. Harris and Dewdney, Barriers to Information.

43. Emily Drabinksi, "Gendered S(h)elves: Body and Identity in the Library," Women and Environments International Magazine (Fall/Winter 2009): 16.

44. Lynn Westbrook, "'I'm Not a Social Worker': An Information Service Model for Working with Patrons in Crises," Library Quarterly: Information, Community, Policy 85, no. 1 (2015): 6-25.

45. Ibid., 13.

46. Mark S. Granovetter, "The Strength of Weak Ties," American Journal of Sociology 78, no. 6 (1973): 1360-1380. Our thanks to Reviewer \#2 for the suggestion to explore this article. 